\title{
Artelogie
}

artelogie Recherche sur les arts, le patrimoine et la littérature de l'Amérique latine

14 | 2019

Sensibilités : Arts, littératures et patrimoine en Amérique latine

\section{O solo da transição: William Hazlitt e a literatura latino americana}

Daniel Lago Monteiro

\section{(2) OpenEdition \\ 12 Journals}

Edição electrónica

URL: http://journals.openedition.org/artelogie/3889

DOI: 10.4000/artelogie.3889

ISSN: 2115-6395

Editora

Association ESCAL

Refêrencia eletrónica

Daniel Lago Monteiro, «O solo da transição: William Hazlitt e a literatura latino americana », Artelogie [Online], 14 | 2019, posto online no dia 07 janeiro 2019, consultado o 18 setembro 2019. URL : http:// journals.openedition.org/artelogie/3889; DOI : 10.4000/artelogie.3889

Este documento foi criado de forma automática no dia 18 Setembro 2019.

Association ESCAL 


\title{
O solo da transição: William Hazlitt e a literatura latino americana
}

\author{
Daniel Lago Monteiro
}

1 A presença de William Hazlitt (1778-1830) na América Latina é discreta, sobretudo quando a comparamos com outros grandes escritores de sua geração, como Walter Scott, Lorde Byron, Samuel Taylor Coleridge, John Keats e Charles Lamb. Os dois primeiros, Byron e Scott, são, sem sombra de dúvidas, os escritores mais populares do chamado Romantismo Britânico e a leitura de suas obras foi decisiva para autores como Álvares de Azevedo, Gonçalves Dias, José de Alencar, entre outros. Algumas dessas obras encontraram traduções em solo americano ainda no século XIX, em geral, via traduções francesas. Em Itinerários de Pasárgada, Manuel Bandeira reconstrói o "dreamwork fabric" do poema Kubla Khan, de Coleridge. "Tomara o poeta", diz Bandeira, "uma dose de ópio e adormecera sentado no momento preciso em que lia no Purchas's Pilgrimage esta frase: 'Aqui o Khan Kubla mandou construir um palácio com suntuoso jardim. E assim dez milhas de terra feraz foram cercadas de muro"' (BANDEIRA, 1967: p. 126). Depois que despertou, Coleridge descobrira que havia composto durante um sonho uns "duzentos ou trezentos versos" (COLERIDGE, 2005: p. 221), os quais dispusera-se prontamente a transcrever. A mesma história foi tema do ensaio de Jorge Luis Borges "O sonho de Coleridge”, em Outras Inquisições. No mesmo livro, há um ensaio sobre Keats "O rouxinol de Keats", no qual Borges lembra a distinção coleridgiana de que "os homens nascem aristotélicos ou platônicos" (BORGES, 2005, p. 139) e que Keats, na contramão do gênio inglês, tinha uma mente platônica, pois seu rouxinol não corresponde ao indivíduo, mas à espécie. Keats é um dos poetas mais admirados por Julio Cortázar, que dedicou a ele um estudo volumoso, Imagen de John Keats, bem como outros ensaios críticos. Mesmo Lamb, que, a exemplo de nosso autor, se destacou sobretudo no gênero ensaio é lembrado por Machado de Assis em Memórias Póstumas de Braz Cubas e no conto $O$ Lapso. Por qual razão a presença de Hazlitt na América Latina é discreta? Neste artigo, procuraremos responder a essa pergunta a partir da noção hazlitiana de que a literatura na modernidade se desenvolve no solo da transição: entre o passado e o futuro, entre uma literatura elevada e outra prosaica e crítica e entre os continentes europeu e americano. Também procuraremos documentar a presença de Hazlitt em alguns escritores e críticos latino americanos. 
2 De saída, convém tecer algumas palavras gerais sobre o nosso autor, sobre sua vida e obra. Hazlitt cresceu em uma família de intelectuais dissidentes que, nos anos de 1790, se refugiara nos Estados Unidos; de volta ao país e depois de ouvir uma pregação de Coleridge, abandonou os estudos pastorais e descobriu sua vocação de filósofo e artista; após uma carreira frustrada de pintor de retratos, passou a ganhar a vida e fez fama literária com ensaios confiados à imprensa periódica; foi defensor ardente da revolução popular; rompeu com o círculo de escritores que, em sua opinião, desertaram a "causa do povo" ${ }^{\prime \prime}$; aos quarenta e quatro anos, divorciou-se de sua primeira esposa na esperança malograda de viver a paixão por uma jovem vinte e cinco anos mais nova; casou-se novamente, morou por alguns anos na Itália e França com a nova esposa, de quem se separaria mais tarde; por fim, terminou a vida só e pobre em um pequeno quarto alugado em Soho, Londres ${ }^{2}$. Quanto à sua obra, vinte e um volumes, segundo a edição centenária de Percival Presland Howe (1930), boa parte dela consiste em ensaios de periódicos. Numa palavra, o "gênio" de Hazlitt era "eminentemente fragmentário"3. Foi assim que o definiu um articulista da New Monthly Magazine, cujo perfil do autor foi traduzido e publicado na Revista Nacional e Estrangeira, Rio de Janeiro (1840), sob o título "Potências Intelectuais da Nossa Idade". Esta é a primeira ocorrência do nome de Hazlitt na imprensa brasileira. 0 perfil se abre com a ideia, cara a nosso autor, de que a época atual, se comparada às anteriores, não produziu "nada de monumental, nada que se dirija ao porvir"4. Falemos mais detidamente sobre essa ideia e, junto a ela, a tese hazlittiana de que as artes não progridem.

3 Numa publicação da Edinburgh Review de 1823, "The Periodical Press", Hazlitt traça um panorama dos principais jornais e revistas literárias inglesas, "o grande opróbio de nossa literatura" (HAZLITT, 1930, v. 16, p. 239). Mas o tom não tem tanta censura quanto a passagem sugere. Hazlitt abre o ensaio ironizando aqueles que se perguntam se "a crítica em periódicos é, no todo, favorável ou não à causa da literatura" (HAZLITT, 1930, v. 16, p. 211); ou se Shakespeare e outros grandes homens de gênio do passado conseguiriam produzir suas obras num tempo em que tudo passa pelo escrutínio do jornal, este "viveiro da crítica" (HAZLITT, 1930, v. 16, p. 211). Não é por aí que se chega a uma solução do problema. Afinal, pergunta Hazlitt, não são Byron e Scott exceções à regra, uma vez que escritores populares cujas obras trazem em si imenso valor literário? Se em cinco ou dez anos elas ainda serão lidas ou se terão adquiridos o ar mofado de velharias, às quais só se retorna por curiosidade histórica, "só o tempo dirá" (HAZLITT, 1930, v. 16, p. 211). Também em tom irônico, conclui o autor, "a crítica em periódicos é favorável à crítica em periódicos" (HAZLITT, 1930, v. 16, p. 212). A partir daí segue-se uma longa discussão sobre o tema ao qual nos referimos acima, a de que não há progresso nas artes.

4 A tese não é decerto original, tampouco ele pretendeu que a fosse. Há nela ecos da crítica que o precedera, sobretudo do século anterior. 0 mote do raciocínio hazlittiano pode ser resumido na seguinte fórmula: quanto mais uma sociedade progride em conhecimento $\mathrm{e}$ refinamento, mais as artes perdem em vigor, gênio criativo e sublimidade. No ensaio de The Round Table, "Why the Arts are not Progressive?", diz ele: "Os maiores poetas, os mais hábeis oradores, os melhores pintores e os mais perspicazes escultores que este mundo já viu surgiram pouco depois do nascimento dessas artes e viveram numa sociedade, sob outros aspectos, comparativamente bárbara" (HAZLITT, 1930, v. 4, p. 161). Este modelo de perfeição, como qualquer outro, implica florescimento, decadência e "a suposição de um ponto máximo a que se pode alcançar nas artes" (SUZUKI, 2014: p. 20), como bem observou Márcio Suzuki acerca de David Hume. Segundo o argumento específico de Hazlitt, por ironia do processo 
histórico, chega-se cedo demais a esse modelo de perfeição. 0 mundo jamais verá outro Homero, outro Ésquilo, outra Safo; não apenas porque foram os primeiros, mas porque levaram à perfeição a arte que, se não as inventaram, contribuíram para dar o acabamento formal a seus respectivos gêneros: épico, dramático e lírico. Todas as alternativas estariam cortadas, restando apenas a decadência ou mesmo o fim da arte, se Hazlitt não incluísse outras duas variantes: 1 - uma forma artística floresce sobre a matéria morta daquela que a antecedeu; 2 - "cada época ou nação possui um padrão que the é próprio" (HAZLITT, 1930, v. 16, p. 215).

5 Quanto a este último argumento, um lugar-comum às poéticas do romantismo, o que o autor diz, por um lado, é que só se pode julgar o mérito de uma obra a partir de valores circunscritos "dentro de limites locais e temporais" (HAZLITT, 1930, v. 16, p. 216); por outro, como não há nenhuma nação que subsista isoladamente, ao menos na modernidade, o contato com o diferente estimula o espírito de emulação; o vigor criativo floresce na vacância. Dante não é superior a Milton, nem este àquele; antes, cada qual atingiu a perfeição na poesia épica de suas respectivas línguas porque souberam trabalhar sobre um material herdado, porém em solo ainda pouco cultivado. Além disso, a barbaridade de suas épocas, as inúmeras dificuldades que se interpunham entre a vontade e a ação, cobrava-lhes um gesto firme e expressivo. Nada mais congênere à natureza da poesia, que, segundo Hazlitt, "é a linguagem da imaginação, das paixões, da fantasia e da vontade" (HAZLITT, 1930, v. 5, p. 8). Não há como não reconhecer no argumento a herança de JeanJacques Rousseau ou de Edmund Burke. Para aquele, a energia expressiva da palavra, própria aos antigos, foi substituída pela necessidade de clareza do homem civilizado, daí o declínio da eloquência e da poesia entre os modernos ${ }^{5}$; para este, as línguas antigas ou orientais são tanto mais sublimes porque dotadas "de uma grande força e energia de expressão" e porque nelas a imaginação prepondera sobre o entendimento, isto é, sobre " as distinções rigorosas." (BURKE, 2013: p. 213).

6 Hazlitt também encontrou na modernidade uma diminuição gradual da força da imaginação, que foi substituída pelo rigor do entendimento. A consequência disso não implica a anulação do entusiasmo, mas a busca por outros, ainda que efêmeros e insaciáveis: os fatos corriqueiros e sem foros de grandeza veiculados pela imprensa.

7 A primeira variante ao mote exposto acima (de que um gênero artístico floresce sobre a decadência de um outro), está, como se pode entrever, intimamente ligada ao segundo. " $A$ tragédia alcançou o ápice na França quando ela estava em declínio entre nós” (HAZLITT, 1930, v. 16, p. 215); assim como, em termos gerais, "a comédia floresceu com o declínio da tragédia" (HAZLITT, 1930, v. 16, p. 214). A explicação, é claro, não pressupõe uma visão absoluta da história, pois a sua marcha não caminha no mesmo passo em diferentes nações; tampouco segundo um fim preconcebido. À luta encarniçada por um ideal, que eleva alguns homens acima dos demais com a corporificação da grandeza de caráter, seguiram-se "as imagens de graça, de alegria e de prazer redobrado (...) sobre a perspectiva de uma vida humana" (HAZLITT, 1930, v. 6, p. 70) não dignificada. Com o advento da comédia, a literatura se mundanizou, novos caminhos se abriram e "novos pedaços de terra, antes negligenciados, foram cultivados" (HAZLITT, 1930, v. 16, p. 215). É verdade que sobre um solo mais amplo, melhor distribuído e, portanto, menos rico em minerais preciosos. Em outras palavras, a literatura e o mundo se tornaram mais prosaicos. "A partir dai", diz ele, "os ensaístas de periódico, Steele e Addison, sucederam nossos grandes escritores de comédia; os romancistas (Fielding, Sterne e Smollett) sucederam aqueles; e cada um deles nos legou obras superiores ao que se produzira antes, ou ao que viria a se produzir desde então" (HAZLITT, 1930, v. 16, p. 215) - é 
verdade que Hazlitt não previra a extensa e rica cultura do romance que floresceria em seu próprio século nas mãos de um Charles Dickens, por exemplo ${ }^{6}$. Seja como for, as condições para o surgimento do romance e do ensaio em periódico - a difusão do conhecimento, a formação do público leitor, "a aproximação e amálgama dos diferentes estratos sociais" (HAZLITT, 1930, v. 16, p. 218), entre outros - foram amplamente analisadas por ele em "The Periodical Press". Vendo o fluxo da história desaguar em solos mais amplos, aplainados e agrupados nos centros urbanos, Hazlitt, aqui, parece acertar em seu prognóstico: "o monarquismo da literatura está com seus dias contados" (HAZLITT, 1930, v. 16, p. 220).

8 Pois bem, poderíamos nos perguntar, e quanto à literatura nas américas? Se o valor de uma obra deve ser julgada "dentro de limites locais e temporais" e se a decadência da literatura e das artes em uma nação implica o seu florescimento noutra, estaria Hazlitt sugerindo que a mais nova e rica produção literária do mundo ocidental ainda estava por nascer nas américas?

Vale lembrar que os anos em que esses ensaios foram redigidos, as décadas de $1810 \mathrm{e}$ 1820, correspondem aos anos de luta pela independência nas américas hispânicas e portuguesas. Evento esse que não passou despercebido por nosso autor, defensor que foi, como disse acima, das revoluções populares. Assim, em um artigo a Morning Chronicle de 1817, Hazlitt assente com o desespero de Lorde Castlereagh (diplomata inglês no Congresso de Viena) quanto "à restauração da paz na América hispânica", contanto que "ele [Castlereagh] incluísse na ideia de paz o reestabelecimento da tirania da forma antiga de governo" (HAZLITT, 1930, v. 7: p. 211). No mesmo ano, Leigh Hunt, amigo de Hazlitt e editor de The Examiner, "um dos principais órgãos do Partido Whig" (MIGUEL PEREIRA, 2016: p. 14), publicou ali um ensaio cujo título chama a nossa atenção: "Revolução no Brasil e a Conquista do Chile". No tocante ao Brasil, Hunt descreve a tentativa de tomado do poder dos colonos naquela que ficou conhecida por Revolução Pernambucana. $O$ ensaio foi escrito no calor da hora e Hunt imaginou que a revolução iria se alastrar por toda a colônia portuguesa na América, como ocorria na América hispânica, tema da segunda parte do ensaio, que trata mais especificamente de José de San Martin. Imbuído do espírito hazlittiano, Hunt argumenta que a chama revolucionária, em declínio na Europa, ressurgia nas américas com "quadros grandiosos de homens derramando triunfantemente seu sangue pela liberdade" (HUNT, 2003, v. 2, p. 112).

Contudo, nem Hazlitt nem Hunt trataram do estado das letras na América Latina. Até porque, não havia ainda uma literatura latino americana stricto senso em sua época. Mas Hazlitt tece algumas considerações sobre a literatura estadunidense, ou melhor, sobre o quanto ela alcançou a maioridade, a independência em relação à Europa. Cito um trecho: "Ele [Estados Unidos da América] é um país novo com uma língua antiga. Mas enquanto tudo em torno dos americanos é novo em folha, eles constantemente recorrem a nós para saber o que pensamos sobre eles e tomam de empréstimo suas opiniões de nossos livros e jornais com uma mistura estranha de servidão e o espírito de contradição. Na política, eles são um povo independente; na literatura, permanecem ainda nossas colônias" (HAZLITT, 1930, v. 17: p. 208).

O mesmo tema será objeto de análise de Roberto Schwarz, que explica a ambivalência das literaturas nas américas, países novos com línguas antigas, pelo conceito de nação periférica. Schwartz lembra que em fins do século XIX Henry James optou por emigrar, pois acreditava que encontraria um solo mais fértil à sua imaginação na Europa: "A minha escolha é o velho mundo - minha escolha, minha necessidade, minha vida (...). Meu trabalho está lá - je n'ai que faire neste vasto novo mundo" (apud. SCHWARZ, 2012: p. 36). No mesmo artigo, 
Schwartz reconstrói o longo percurso que Alencar e Machado tiveram de percorrer para dar uma forma brasileira, uma "cor local" (MACHADO, 2017: p. 58), nas palavras de Machado, aos grandes temas e "ao bom modelo do romance (europeu)" (SCHWARZ, 2012: p. 42). Tanto a alternativa de James, de abraçar o velho mundo, quanto as de Alencar e Machado acenam para o que diz Hazlitt no trecho citado antes, a literatura nas américas mantêm uma interdependência com a europeia. Assim como Schwarz, Hazlitt sabe que as formas literárias não estiveram sempre lá, "pront[as] desde sempre", mas que surgiram " sobre o solo da transição" (SCHWARZ, 2012: p. 38) de um regime de governo ou econômico a outro.

O romance enquanto epopéia da era burguesa, segundo a célebre formulação de Lukács, foi o gênero adotado por algumas das principais vozes literárias do continente americano no século XIX. Mas, junto ao romance, floresceria nas américas as formas fragmentárias, sem foros de grandeza, como a crônica jornalística de Alencar e Machado, a contística de Edgar Allan Poe e as memórias e ensaios de Domingo F. Sarmiento. Em certo sentido, a literatura nasce nas américas e na América Latina em especial sobre o terreno amplo e aplainado da prosa do mundo. Numa palavra, uma literatura crítica, segundo os critérios de nosso autor. É essa mesma literatura fragmentária, prosaica e crítica que, vez ou outra, irá se remeter a Hazlitt, "o grande ensaísta" (CARPEAUX, 1966: p. 2012), nas palavras de Otto Maria Carpeaux.

Abrimos este artigo com um breve recenciamento de escritores latino americanos que incorporaram o Romantismo Britânico à sua literatura. Resta, por fim, dizer uma palavra ou outra sobre a presença de Hazlitt na América Latina, com a qual procuraremos responder às perguntas: qual a sua relevância para nós, latino americanos? Ou ainda, por que ler Hazlitt na América Latina e, em particular, no Brasil?

Dos grandes escritores latino americanos, Borges é decerto o mais anglófilo, sem que isso lhe diminuísse seu espírito latino americano e, mais ainda, universalista. Borges foi alfabetizado nos dois idiomas, espanhol e inglês. "Em casa", diz Borges no Ensaio Autobiográfico, "falávamos indistintamente em espanhol em inglês" (BORGES, 2009, p. 16). Por influência de sua avó, Fanny Haslam, e de seu pai travou contato com um vasto repertório de autores de língua inglesa. Anos mais tarde, ele ministrou um curso de literatura inglesa em vinte e cinco aulas na Universidade de Buenos Aires. Hazlitt ficou de fora desse curso, mas sua presença, ainda que esparsa, é notável nos ensaios. É possível que o primeiro contato de Borges com Hazlitt se deu por intermédio de dois de seus escritores favoritos, Shakespeare e Robert Louis Stevenson. Davi Arrigucci Jr. lembra que "Borges vincula seus exercícios de prosa narrativa à releitura de Stevenson" (STEVENSON, 2011: p. 25). Ao passo que Stevenson vinculou seus exercícios de prosa a Hazlitt. Assim, lemos a frase em "A College Magazine”, citada por Borges, "macaquei Hazlitt com afinco" (STEVENSON, 1990: pp. 42-3)7. Anos mais tarde, quando já gozava de grande prestígio entre a crítica e o público, Stevenson se dirigiu aos escritores de sua geração dizendo: "Ainda que sejamos pessoas admiráveis, jamais escreveremos como William Hazlitt" (Apud. REYES, 1963, v. 5: p. 346)ำ. São inúmeros os contos e ensaios de Borges que se reportam a Shakespeare - como não haveria de sê-lo para uma literatura, como a de Borges, eminentemente calcada nos grandes monumentos da cultura ocidental? Depois de Hazlitt, é impossível ler Shakespeare como leram Samuel Johnson e outros críticos que o precederam. Em Characters of Shakespeare's Plays (1817), Hazlitt analisa peça por peça do dramaturgo com ênfase nos traços individuais, psicológico e nuances de estilos linguísticos das personagens que, em sua grande parte, dão título às obras: Hamlet, MacBeth, Otelo, 
Romeu e Julieta, etc. Mas a tese central nesse livro é, por assim dizer, anti-individualista. No ensaio de Borges "De alguém para ninguém", ele cita uma passagem de Hazlitt que sintetiza o seu entendimento de Shakespeare: "Shakespeare em tudo se assemelhava a todos os homens, exceto no fato de assemelhar-se a todos os homens. No íntimo não era nada, mas era tudo o que os homens são, ou o que podiam ser" (BORGES, 2005: pp. 169-70). A mesma ideia reaparece no ensaio "Valéry como símbolo". Valéry, segundo Borges, "transcende os traços individuais do eu" e dele se pode dizer, "como Hazlitt disse de Shakespeare: "He is nothing in himself"' (BORGES, 2005: p. 93).

Em suma, o traço predominante do Hazlitt lido por Borges é do crítico. Como foi para Julio Cortázar. Nos anos de 1818-19, Hazlitt ministrou três cursos de literatura inglesa. Keats assistiu a algumas dessas aulas e ficou particularmente tocado com ideia de que Shakespeare, o maior dos poetas ingleses, no íntimo não era ninguém, "mas era tudo o que os homens são, ou podem ser" (HAZLITT, 1930, v. 5: p. 47). Foi com base nessa ideia que Keats desenvolveu o conceito de "negative capabiblity" (KEATS, 2002: p. 60), isto é, de que o poeta não tem uma identidade própria, e que, sob esse aspecto, é a menos poética das criaturas. Contudo, é isso que lhe permite se transmutar em todos os seres: "O sol, a lua, o mar, homens e mulheres" (KEATS, 2002: p. 195). Cortázar identificou nesse princípio a base para a fancy de Keats. Nenhum outro contemporâneo, diz Cortázar, expressou uma admiração tão profunda por Hazlitt quanto Keats. Aquele foi o "Domingo Faustino Sarmiento da crítica inglesa" (CORTÁZAR, 2004: p. 224). Uma afirmação bastante elogiosa, pois, como se sabe, Sarmiento foi não apenas o grande estadista, mas fundador da literatura nacional argentina.

16 Citamos acima a frase de Otto Maria Carpeaux que abre o perfil que escreveu do ensaísta em História da Literatura Ocidental (1959-66) ${ }^{9}$. Carpeaux, com sua rara sensibilidade, que combina aptidões que a especialização universitária manda separar, não se deixou enganar, como ocorrera a outro crítico de sua geração, o italiano Mario Praz, quanto ao lugar que Hazlitt merecidamente ocupa na literatura: o de ter sido um de seus maiores ensaístas $^{10}$. Entretanto, há alguns deslizes nesse perfil que devem ser pontuados. Primeiro, Hazlitt jamais foi um defensor do individualismo e discípulo de Helvetius; pelo contrário, sua filosofia é um tapa na cara das teorias que fundamentam a ação humana no indivíduo e no amor-próprio. Segundo, não pode haver qualquer afinidade entre Hazlitt e Jeremy Bentham, senão por oposição. Por toda a vida, Hazlitt encampou a batalha contra a suposição de que a razão instrumental conduziria a humanidade às verdades concretas $\mathrm{e}$ à construção de uma sociedade mais justa. Terceiro, o bonapartismo de Hazlitt não guarda semelhanças com o culto ao herói de Carlyle. Se, para Carlyle, Napoleão, o "último dos grandes homens" (CARLYLE, 1841: p. 392), era dotado de uma habilidade que naturalmente exercia um "direito divino sobre" (CARLYLE, 1841: p. 321) os outros; para Hazlitt, o estadista foi um condutor da causa revolucionária, e isso "a despeito de si mesmo" (HAZLITT, 1930, v. 7: p. 9). Sem que o soubesse, Napoleão era incapaz de "despir-se de seu caráter"; isto é, o de "filho e campeão da Revolução Francesa" (HAZLITT, 1930, v. 13: p. ix)"

17 Em ocasiões distintas, e com propósitos igualmente distintos, Hazlitt foi lido por duas personalidades emblemáticas da intelectualidade brasileira modernista. Uma, a romancista e ensaísta Lucia Miguel Pereira; a outra, um dos maiores poetas e compositores de nossa língua, Vinícius de Moraes.

Lucia Miguel Pereira prefaciou o volume Ensaístas Ingleses (1952), tradução de J. Sarmento de Beires e Jorge Costa Neves. Neste apareceram as duas primeiras traduções de Hazlitt para o português brasileiro: "Sobre a Ignorância dos Sábios" e "A Propósito de Alcunhas". 
O volume foi inspirado em outra coletânea, mais extensa, Ensaysitas Ingleses (1948), prefácio de Adolfo Bioy Casares. Se Casares ressaltou a versatilidade dos talentos de Hazlitt (pintor, filósofo, historiador, ensaísta), Miguel Pereira lembrou, sobretudo, a qualidade do crítico que facilita a compreensão histórica: "seus ensaios críticos, que abrangem praticamente todos os escritores desde a época de Elizabeth até a sua, contribuíram largamente para o entendimento de Shakespeare, assim como para o movimento romântico na Inglaterra" (MIGUEL PEREIRA, 2016: p. 14). Mas ambos, Casares e Miguel Pereira, foram sensíveis ao fervor apaixonado, e apaixonante, de seus ensaios. "Hazlitt pensou muito, escreveu muito e combateu muito" (CASARES, 1957: p. 14), disse Casares. Ou ainda, nas palavras de Miguel Pereira: "temperamento espontâneo, os escritos lhe refletem as paixões, as simpatias e antipatias" (MIGUEL PEREIRA, 2016: p. 14).

Noutra chave, mas também perto do coração, o Hazlitt de Vinicius de Moraes é o cronista que em épocas de epidemia mantém a dignidade de jamais ceder ao entreguismo. Em $O$ Exercício da Crônica (1953), contrariando a opinião de que este seria um gênero tipicamente brasileiro, de que teria se aclimatado aqui melhor do que em qualquer outra parte do mundo ${ }^{12}$, Moraes diz que a crônica é filha do ensaio, ou melhor, do essay. A passagem merece ser lida na íntegra: "Os melhores cronistas do mundo, que foram os do século XVIII, na Inglaterra - os chamados essayists -, praticaram o essay, isto de onde viria a sair a crônica moderna, com um zelo artesanal tão proficientes quanto a de um bom carpinteiro ou relojoeiro. Libertados da noção exclusivamente moral do primitivo essay, os oitocentistas ingleses deram à crônica suas primeiras lições de liberdade, casualidade e lirismo, sem perda do valor formal e da objetividade. Addison, Steele, Goldsmith e sobretudo Hazlitt e Lamb - estes os dois maiores - fizeram da crônica, como um bom mestre carpinteiro o faria com uma cadeira, um objeto leve mas sólido, sentável por pessoas gordas ou magras" (MORAES, 2009: p. 53).

Pois bem, Hazlitt foi um dos maiores cronistas; foi mestre de um estilo que aposta na aliança produtiva entre a intelectualidade e a vida popular; foi um crítico atento ao processo histórico; foi também um intelectual não conformista e talvez o único de sua geração que se declarou, acima de tudo, um revolucionário ${ }^{13}$. Com a feliz confluência de traços estilísticos e ideais preciosíssimos para um grande batalhão de professores universitários de origem esquerdista entre nós, talvez devêssemos inverter a pergunta: afinal, por que Hazlitt permanece um autor negligenciado no Brasil? A resposta talvez esteja precisamente no argumento de Hazlitt de que a literatura e a crítica andam, ou deveriam andar, de mãos dadas na modernidade. Para os escritores latino americanos que souberam reconhecer o modo como a crítica e a inventividade influem uma sobre a outra e que trabalharam sobre o solo da transição - entre o passado e o futuro, entre uma literatura elevada e outra prosaica e crítica e entre os continentes europeu e americano -, Hazlitt, dizia Vinicius de Moraes, está entre os maiores.

\section{BIBLIOGRAFIA}

BANDEIRA, Manuel. Poesia Completa e Prosa. José Aguilar Editora, Rio de Janeiro, 1967.

CASARES, Adolfo Bioy. Ensayistas Ingleses. Éxito, Barcelona, 1957. 
BORGES, Jorge Luis. Outras Inquisições. Companhia das Letras, São Paulo, 2005.

BORGES, Jorge Luis. Ensaio Autobiográfico. Companhia das Letras, São Paulo, 2009.

BURKE, Edmund. Uma Investigação Filosófica sobre a Origem de Nossas Ideias do Sublime e do Belo. Editora Unicamp, Campinas, 2013.

CANDIDO, Antônio. Recortes. Companhia das Letras, São Paulo, 1993.

CARLYLE, Thomas. On Heroes and Hero-Worship. Charles Scribner's Sons, New York, 1841.

CARPEAUX, Otto Maria. História da Literatura Ocidental, vol. "Romantismo”. Ed. Cruzeiro, Rio de Janeiro, 1966.

COLERIDGE, Samuel Taylor. A Balada do Velho Marinheiro. Ateliê Editorial, São Paulo, 2005.

CORTÁZAR, Julio. Imagen de John Keats. Punto de Lectura, Buenos Aires, 2004.

HAZLITT, William. The Complete Works of William Hazlitt, ed. P. P. Howe. J. M. Dent and Sons, LTD, London and Toronto, 1930, 21 vols.

HUNT, Leigh. The Selected Writings of Leigh Hunt, 6 vols. Pickering \& Chatto, London, 2003.

KEATS, John. Selected Letters. Harvard University Press, Cambridge, 2002.

MACHADO, de Assis. O Espelho. Editora Unicamp, Campinas, 2017.

MIGUEL PEREIRA, Lúcia. “Sobre os Ensaístas Ingleses”, In. Serrote \#22. Instituto Moreira Salles, São Paulo, 2016.

MORAES, Vinícius de. "O Exercício da Crônica”, In. Para uma Menina com uma Flor. Companhia das Letras, São Paulo, 2009.

PAULIN, Tom. "Hazlitt's Influence on Dickens in Baraby Rudge", In. The Hazlitt Review, vol. 2. The Hazlitt Society, London, 2009.

PRAZ, Mario. “Is Hazlitt a great essayist?” In English Studies. 1931, pp. 1-6.

Revista Nacional e Estrangeira. Rio de Janeiro, 1840.

REYES, Alfonso. Obras Completas de Alfonso Reyes, IX. Fondo de Cultura Económica, Cidade do México, 1952.

ROUSSEAU, Jean-Jacques. Ensaio Sobre a Origem das Línguas. Editora Unicamp, Campinas, 2003.

SCHWARTZ, Roberto. Ao Vencedor as Batatas. Editora 34, São Paulo, 2012.

STEVENSON, Robert Louis. Memories and Portraits. Richard Drew Publishing, Glasgow, 1990.

STEVENSON, Robert Louis. O Clube do Suicídio e outras histórias. Apresentação Davi Arrigucci Jr. Cosacnaify, São Paulo, 2011.

SUZUKI, Márcio. A Forma e o Sentimento do Mundo: Jogo, humor e arte de viver na filosofia do século XVIII. Editora 34, São Paulo, 2014.

\section{NOTAS DE FIM}

1. Todas as citações de Hazlitt, salvo as vezes que indicar em nota, foram extraídas de The Complete Works of William Hazlitt, 21 vols. (London and Toronto: J. M. Dent and Sons, LTD, 1930). Daqui em diante, usaremos a sigla $\mathrm{CWH}$, seguida do nome do texto de onde extraímos a citação e os números do volume e das páginas. Ver "What is the People?", CWH, 7, p. 261. 
2. Um dos últimos ensaios de Hazlitt se chama "London Solitude" que se abre com as palavras: "Em Londres, tudo se consegue com dinheiro, mas há uma coisa que pode ser alcançada em sua perfeição sem ele. Esta é a solitude". In All That is Worth Remembering, Widworthy Barton Honiton: 2014, p. 160.

3. “Galeria Biographica”, In. Revista Nacional e Estrangeira, Rio de Janeiro, 1840, p. 250.

4. Idem, p. 249.

5. Jean-Jacques Rousseau, Ensaio sobre a Origem das Línguas (Campinas: Editora Unicamp, 2003), pp. 175-6. Sobre o tema, ver Bento Prado Jr., A Retórica de Rousseau e outros ensaios (São Paulo: Cosac \& Naify, 2008), pp. 118-9.

6. Sobre as inúmeras conexões entre Dickens e Hazlitt, ver Tom Paulin, "Hazlitt's Influence on Dickens in Baraby Rudge”, In. The Hazlitt Review, vol. 2 (London: The Hazlitt Society, 2009), pp. 5-20.

7. A frase de Stevenson é bastante conhecida e foi citada por Jorge Luis Borges em Esse Ofício do Verso (São Paulo: Companhia das Letras, 2000), p. 97.

8. Citado a partir de David Bromwich, Hazlitt: The Mind of a Critic, (New Haven: Yale University Press, 1999), p. 3. Adolfo Bioy Casares também cita esta passagem no prólogo a Ensayistas Ingleses (Barcelona: Éxito, 1957), p. 14.

9. Otto Maria Carpeaux, História da Literatura Ocidental, Vol. "Romantismo”, pp. 2012-2013.

10. Ver Mario Praz, "Is Hazlitt a great essayist?” (English Studies, 1931), pp. 1-6.

11. A melhor discussão sobre Hazlitt e Napoleão é de Simon Bainbridge, "'A proud and full answer': Hazlitt's Napoleonic riposte", In. Napoleon and English Romanticim (Cambridge: Cambridge University Press, 1995), pp. 183-207.

12. É dessa opinião Antônio Candido. Sobre a crônica, diz Candido: "sob vários aspectos é um gênero brasileiro, pela naturalidade com que se aclimatou aqui e a originalidade com que aqui se desenvolveu" (CANDIDO, 1993: p. 24).

13. Hazlitt fez sua profissão de fé política precisamente na última de suas publicações, Life of Napoleon. No capítulo "The Establishment of the Empire", diz ele: "Nunca e em parte alguma de meus escritos declarei-me um republicano; tampouco creio que valha a pena ser um mártir e defensor desta ou daquela forma de governo. Mas se arrisquei minha saúde e riqueza, meu nome e fama a alguma coisa, a qual estaria disposto a me arriscar novamente e até a última gota de suor, foi à ideia de que há um poder no povo para mudar o seu governo e governantes. Numa palavra, sou um revolucionário", (HAZLITT, 1930, v. 14: p. 236). Para uma discussão sobre essa passagem, ver Gilmartin “Revolutionist”, In. William Hazlitt, Political Essayist, pp. 186-200.

\section{RESUMOS}

O presente artigo se propõe tanto a documentar a presença de William Hazlitt (1778-1830) na América Latina quanto a analisar aqueles escritos do autor nos quais ele comenta a situação política e literária do Novo Mundo. Ainda que discreta, essa presença é notável em alguns dos escritores mais renomados da América Latina. Seguindo o argumento de Hazlitt de que não há progresso nas artes, trabalharemos com a sugestão do autor de que, de um lado, a mais nova e rica produção literária do mundo ocidental ainda estava por nascer nas américas, do outro, que essa mesma literatura irá se desenvolver sobre o solo da transição: entre o passado e o futuro e entre os continentes europeu e americano.

Le présent article propose de documenter la présence de William Hazlitt (1778-1830) en Amérique latine. Il analyse ses commentaires sur la situation politique et littéraire du Nouveau Monde. Bien que discrète, cette présence est remarquable chez certains des écrivains les plus renommés du continent. En suivant l'argument de Hazlitt selon lequel il n'y a pas de progrès 
dans les arts, nous discuterons sa thèse selon laquelle la production littéraire la plus riche du monde occidental était encore à naître dans les Amériques et que cette même littérature se développerait sur un terrain de transition : entre le passé et l'avenir et entre les continents européen et américain.

ÍNDICE

Mots-clés: William Hazlitt, Littérature latino-américaine, Littérature anglaise, Essai, Critique.

Palavras-chave: William Hazlitt, Literatura Latino Americana, Literatura Inglesa, Ensaio, Crítica.

\section{AUTOR}

\section{DANIEL LAGO MONTEIRO}

Doutor em teoria literária e literatura comparada, Universidade de são Paulo E-mail: daniel.l.monteiro@hotmail.com 